\title{
UNILATERAL MENIERE'S DISEASE; INTRA TYMPANIC INJECTION OF LOW DOSE GENTAMICIN IN THE TREATMENT
}

1. Professor and Consultant Surgeon ENT

Islamabad Medical \& Dental College, Pakistan

2. Assistant Professor ENT

Pakistan Institute of Medical

Sciences Pakistan

3. Consultant Surgeon ENT Jeddah National Hospital Jeddah KSA

4. Consultant Surgeon ENT NESCOM Hospital Pakistan

5. Consultant Surgeon ENT Islamabad Medical \& Dental College Pakistan

Correspondence Address:

Prof. Wajahat Bangash

(Consultant surgeon ENT, Islamabad Medical \& Dental College,

Barakahu, Islamabad, Pakistan

44000)

wajahatukb@yahoo.co.uk

Article received on:

15/10/2015

Accepted for publication:

12/11/2015

Received after proof reading:

$13 / 01 / 2016$
Prof. Wajahat Bangash', Dr. Altaf Hussain², Dr. Muhammad Javed Aslam³ ${ }^{3}$ Dr. Atif Sharif ${ }^{4}$, Dr. Tallat Najeeb ${ }^{5}$

ABSTRACT: Meniere's disease is chronic progressive disease with unclear idiopathic etiology and symptomatic improvements with treatment. Objectives: To analyze the efficacy of low dose intratympanic injection of gentamicin for vertigo control in unilateral Meniere's disease. Study Design: Quasi experimental study. Settings: Department of ENT, PIMS, NESCOM \& IMDC Islamabad. Materials \& Methods: Gentamicin was used intra tympanically in this multicentre study of 75 patients over a period of 8.5 years between $1^{\text {st }}$ January 2005 to $30^{\text {th }}$ June 2013 in definite Meniere's disease according to the 1995 Document of American academy of otolaryngology- Head and Neck Surgery (AAO-HNS).All these centers followed same criteria and procedures. Single dose of $1 \mathrm{ml}$ Gentamicin solution $40 \mathrm{mg} / \mathrm{ml}$ was instilled in the middle ear through the grommet under microscope and followed up for 3 months and two years. The staging of disease (hearing thresholds) the degree of disability (frequency of attacks per month) and the functional level were assessed before and after treatment. Results: Among 75 patients, 41 were female \& 34 were males between age ranges of 25 to 70 years. Most of the patients in the study had stage $2(23 / 75)$ and stage 3 (41/75) Meniere's disease. About 68(91\%) patients were having good control of vertigo at the end of two year of intratympanic gentamicin without any loss of hearing. Conclusion: A single Low dose intratympanic gentamicin is effective in controlling vertigo in patients with Meniere's disease with no further deterioration in hearing for at least two years follow up.

Key words: $\quad$ Meniere's disease, Gentamicin, Intratympanic

Article Citation: Bangash W, Hussain A, Aslam MJ, Sharif A, Najeeb T. Unilateral Meniere's disease; intra tympanic injection of low dose gentamicin in the treatment. Professional Med J 2016;23(1):093-098. DOI: 10.17957/TPMJ/16.3129

\section{INTRODUCTION}

Meniere's disease is chronic progressive disease characterized by debilitating vertigo, fluctuating sensorineural hearing loss with and without tinnitus and aural fullness. The actual cause of Meniere's disease is still unclear but the main patho-physiology is idiopathic endolymphatic hydrops. ${ }^{1}$ The natural course of Meniere's disease is variable but the symptoms mainly result from a decline in function of peripheral vestibular system and a progressive sensorineural hearing loss. ${ }^{2}$ Meniere's disease is treated by lifestyle modifications and medications initially and surgery is reserved for chronic debilitating vertigo not responding to medications. Vertigo is the most bothersome symptom in patients with Meniere's disease. Studies have shown that vertigo results in physical handicap while tinnitus \& hearing loss results in psychosocial problems. ${ }^{3}$ There is no permanent cure for Meniere's disease till this time and interventions are aimed at symptomatic treatment to improve quality of life of the patients.

Gentamicin is an aminoglycoside antibiotic and over the last two decades it is frequently being used in the treatment of bothersome vertigo, in patients with Meniere's disease. ${ }^{4}$ Gentamicin is considered to be more vestibulotoxic than cochleotoxic, and Intratympanic gentamicin therapy has currently become popular all over the world for treatment of unresponsive vertigo in Meniere's disease. ${ }^{5,6}$ The aim of instillation of gentamicin in middle ear is to cause damage to the vestibular epithelium, resulting in control of vertigo while preserving the hearing. ${ }^{7}$ There are different regimens which advocate different doses of gentamicin to be instilled in the middle ear for the treatment of vertigo in patients suffering 
from Meniere's disease. These are high dose and low dose regiments. In high dose regiments the popular techniques are multiple daily dosing technique (delivery, 3times per day for more than 4 days), weekly dosing technique (weekly injections for 4 total doses), continuous micro catheter delivery and titration technique (daily or weekly doses until the symptoms subsided) while in low dose technique (1-2 injection are used or it can be repeated with recurrent vertigo). It has been shown by studies that the degree of vertigo control is not related to the amount of damaged vestibular epithelium. ${ }^{4}$ There are many studies on dosing regimens but till this time there is no consensus on the dose and the frequency of the gentamicin to be instilled that offers maximal control of vertigo with minimal complications. ${ }^{8}$ Most consider that once gentamicin imbibes in the inner ear, its elimination from inner ear is a prolonged process and it is assumed that it may take up to 3 weeks or more for gentamicin to be eliminated from inner ear. ${ }^{9}$

We planned our study with low dose of gentamicin and used $40 \mathrm{mg} / \mathrm{ml}$, lower than used in many studies. Our aim was to see how effective this dose is in controlling vertigo with minimal hearing loss. We gave only one injection in majority of the patients \& initially recorded response after 3 months with encouraging and in few cases where the response was limited; we repeated the same dose and then followed for two years.

\section{MATERIAL AND METHODS}

This was a multicentre study carried out at Pakistan Institute of Medical Sciences (PIMS) Islamabad, National Engineering and Scientific Commission (NESCOM) hospital, Islamabad, and Islamabad Medical \& Dental College (IMDC) hospital, Islamabad. The study was carried out by three independent ENT consultants \& their teams at three Institutes. All the three centers followed same criteria and procedures mentioned below. The study was carried out for 8 years and 6 months

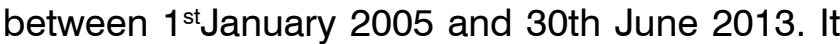
was Quasi-experimental study. Non purposive convenience sampling technique was used. Patients meeting all the inclusion and exclusion criteria were enrolled in the study.

\section{Inclusion criteria}

- Unilateral definite Meniere's disease according to AAO-HNS 1995 document.

- Patients had tried low salt diet, and medical treatment (Diuretics and Betahistine) for at least 2 years without any improvement.

- Informed consent of patient regarding willingness for treatment.

\section{Exclusion criteria}

- Any middle ear or mastoid disease of the affected ear.

- Contra lateral ear pathology or hearing loss.

- Previous treatment with Intratympanic gentamicin somewhere else.

- Any intracranial pathology.

- Psychologically unstable patients.

All patients were evaluated by detailed history, thorough ear, nose, throat, and neurological examination to identify and classify Meniere's disease. CT scan of temporal bone was ordered in those patient suspected of middle ear cleft disease. MRI scan of brain was done in every patient to rule out any pathology pertaining to central nervous system. After that all patients had PTA, at .5, 1, 2, and $3 \mathrm{kHz}$ (Average of these four frequencies was used in the present study in accordance with 1995 AAO-HNS document).

Patients were explained about the procedure and informed consent was taken. The procedure was carried out in operating room, under microscope using local anesthesia (2\% Lignocaine with adrenaline). Myringotomy was done according to the plan in posterior- inferior quadrant of tympanic membrane of the diseased ear instead of anteroinferior quadrant and a grommet was inserted.1 $\mathrm{ml}$ of gentamicin solution, $40 \mathrm{mg} / \mathrm{ml}$, was instilled through 24 gauge spinal needle through the grommet in the middle ear cavity. The position of patient was maintained with the affected ear upper most for about 30 minutes. Nystagmus was observed during the procedure. Patient was advised not to swallow. All these patients were treated as a day case. Patients were prescribed 
Cinnarizine $75 \mathrm{mg}$ per day and Betahistine $64 \mathrm{mg}$ per day for 7 days, and advised to continue these medications if they experienced vertigo after wards till it subsided.

The data of patients including name, age, sex, address and the side involvement were entered into a Performa designed for this study. Same Performa was available to all the doctors in three different settings. In addition to the personal data of the patients, the average hearing threshold level, frequency of vertiginous attacks, the functional level and the control level (according to AAO-HNS document 1995) were also maintained. The patients were followed monthly for first three months and then every third month till 2years. Any improvement or otherwise were recorded on the same Performa after 3 months and 02 years.

\section{RESULTS}

Initially 82 patients were recruited in the study but 4 patients were lost to the follow up \& in 3 patients treatment had to be stopped because of severe vertigo $\&$ refusal by the patient to continue the treatment.

A total of 75 patients were included in the study with $41(54.6 \%)$ female and $34(45.4 \%)$ males. In 47 patients right sided and in 28 patients left sided disease identified. Age of the patients ranged between 25 to 70 years with a mean age of 44.5 years (Table-IV). Most of the patients included in the study had stage 2 and stage 3 Meniere's disease (Table-IV). Number of attacks of vertigo per month at the start of study and at follow up is shown in Table-V. Also the functional level scale of patients according to AAO-HNS 1995 document before and after treatment is shown in Table-VI.

At initial recorded follow up at three months 32/75 $(45.33 \%)$ patients were having class A control i.e. they were free of vertigo (Table-VI) and 29/75 $(38.66 \%)$ patients were in class B control which means substantial control of vertigo. While at follow up at 2 years 35/75 (46.66\%) patients were having class A control and in 33/75 (44\%) patients had class $B$ control level. Which means about 91\% patients (class $A+$ class $B$ ) was having good control of vertigo at the end of 2 years after Intratympanic gentamicin injection. Those patients in class $\mathrm{C}$ control of vertigo category, many of them stated that their attacks of vertigo were not as severe as were before the treatment.

14 patients had control level grade $\mathrm{C}$ at three month follow up and were given second injection of Intratympanic gentamicin with good control of vertigo at 2 years of follow up.

The hearings of all patients were evaluated at 2 years follow up. Only 6 patients had deterioration in hearing ranging from 5 to $15 \mathrm{~dB}$, and of these only $3(4 \%)$ had hearing deterioration of $10 \mathrm{~dB}$ or more (According to AAO-HNS 1995 document Pure tone audiometery average is considered improved or worse if a $10 \mathrm{~dB}$ difference is noted).

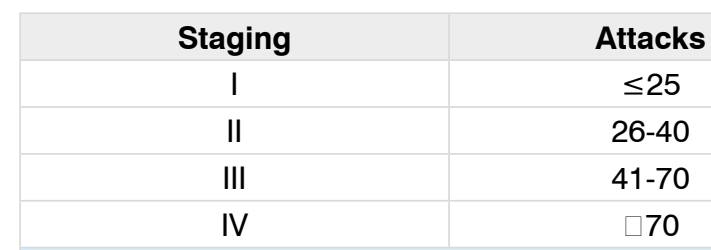

Table-I. Staging of Meniere's disease (AAO-HNS CHE 1995)

1. Dizziness has no effect on activities at all.

2. When dizzy, stops for a while, resume activities and continue and no changes in any plans or activities.

3. When dizzy, stops working, resume in a while and continue but have had to change some plans and activities.

4. When dizzy, stops working, but only resume it is most essential because it exerts a great deal of effort to do so.

5. Disabled due to dizziness, can't work, drive, travel or take care of family. Essential activities are limited.

6. Disabled for more than one year and receiving compensation (money) because of dizziness.

Table-II. Functional level scale (AAO-HNS CHE 1995)

$\frac{\text { Average } \frac{\text { spells }}{\text { months }} \text { post treatment }(24 \text { months })}{\text { Average } \frac{\text { spells }}{\text { months }} \text { pretreatment }} \times 100=$

level of control 


\begin{tabular}{|c|c|c|}
\hline LEVEL & SCORE & Level of control \\
\hline A & 0 & Complete control \\
\hline B & $1-40$ & Substantial control \\
\hline C & $41-80$ & Limited control \\
\hline D & $81-120$ & Insignificant control \\
\hline E & $>120$ & Worse control \\
\hline Table-III. Control level (Vertigo treatment reporting \\
standard) (AAO-HNS CHE 1995)
\end{tabular}

\begin{tabular}{|c|c|c|}
\hline STAGING & No. of Patients & \%age \\
\hline STAGE I & 8 & $10.66 \%$ \\
\hline STAGE II & 23 & $30.66 \%$ \\
\hline STAGE III & 42 & $56 \%$ \\
\hline STAGE IV & 2 & $2.66 \%$ \\
\hline & AGE \\
\hline $25-35$ & 10 & \\
\hline $36-45$ & 24 & $13.3 \%$ \\
\hline $46-55$ & 16 & $32 \%$ \\
\hline $56-65$ & 15 & $21.3 \%$ \\
\hline $66-75$ & 5 & $20 \%$ \\
\hline
\end{tabular}

Table-IV, Staging of Meniere's Disease and Age Distribution (n 75)

\begin{tabular}{|c|c|c|c|}
\hline $\begin{array}{c}\text { Average no. } \\
\text { of attacks } \\
\text { of Vertigo/ } \\
\text { month }\end{array}$ & $\begin{array}{c}\text { Before start of } \\
\text { treatment }\end{array}$ & $\begin{array}{c}\text { After 03 } \\
\text { months }\end{array}$ & $\begin{array}{c}\text { At 02 } \\
\text { years }\end{array}$ \\
\hline 0 & - & $\begin{array}{c}29 / 75 \\
(38.66 \%)\end{array}$ & $\begin{array}{c}32 / 75 \\
(42.66 \%)\end{array}$ \\
\hline 1 & - & $\begin{array}{c}28 / 75 \\
(37.33 \%)\end{array}$ & $\begin{array}{c}30 / 75 \\
(40 \%)\end{array}$ \\
\hline 2 & $20 / 75(26.66 \%)$ & $11 / 75$ & $10 / 75$ \\
\hline & $(14.66 \%)$ & $(13.33 \%)$ \\
\hline 3 & $28 / 75(37.33 \%)$ & $7 / 75$ & $3 / 75(4 \%)$ \\
\hline 4 & $15 / 75(20 \%)$ & - & - \\
\hline 5 & $8 / 75(10.66 \%)$ & - & - \\
\hline 6 & $3 / 75(4 \%)$ & - & - \\
\hline 7 & $1 / 75(1.33 \%)$ & - & - \\
\hline
\end{tabular}

Table-V. Average Attacks of Vertigo per Month ( $n$ 75) [AAO-HNS 1995]

\begin{tabular}{|c|c|c|}
\hline $\begin{array}{c}\text { Functional level } \\
\text { scale }\end{array}$ & $\begin{array}{c}\text { Before start of } \\
\text { treatment }\end{array}$ & \begin{tabular}{c} 
After 02 years \\
\hline 1
\end{tabular} \\
\hline 2 & - & $5 / 75(6.66 \%)$ \\
\hline 3 & $23 / 75(30.66 \%)$ & $34 / 75(45.33 \%)$ \\
\hline 4 & $32 / 75(42.66 \%)$ & $33 / 75(44 \%)$ \\
\hline 5 & $14 / 75(18.66 \%)$ & $2 / 75(2.66 \%)$ \\
\hline $\begin{array}{c}\text { CONTROL LEVEL } \\
\text { OF VERTIGO }\end{array}$ & AT 03 MONTHS & AT 02 YEARS \\
\hline A & $32 / 75(45.33 \%)$ & $35 / 75(46.66 \%)$ \\
\hline B & $29 / 75(38.66 \%)$ & $33 / 75(44 \%)$ \\
\hline C & $14 / 75(18.66 \%)$ & $7 / 75(9.33 \%)$ \\
\hline
\end{tabular}

Table-VI. Functional Level \& Control of Vertigo (n 75) [AAO-HNS 1995]

\section{DISCUSSION}

Intratympanic gentamicin is becoming the standard treatment of persistent un-resolving vertigo in patients with Meniere's disease. ${ }^{4}$ still there is no agreement on the most appropriate dose of gentamicin, which results in control of vertigo and has no side effects especially hearing loss. Chia et al have given a very good description of the different dosing regimens used in the treatment of vertigo in patients with Meniere's disease. Broadly speaking many authors use the term High dose and Low dose regimens. ${ }^{4}$ It has been argued by many that for effective control of vertigo in Meniere's disease the vestibular epithelium should be completely destroyed by repeated use of Intratympanic gentamicin with the belief that partial destruction of vestibular function is not helpful in many patients to completely control their vertigo. ${ }^{9}$ Zhai et al had shown that after Intratympanic injection of gentamicin there is rapid uptake of gentamicin by the vestibular epithelium and slow elimination which takes 3 weeks. Other studies have shown that total ablation of vestibular epithelium in not necessary to control vertigo in Meniere's disease. ${ }^{4}$

We planned our study with low dose of gentamicin and used $40 \mathrm{mg} / \mathrm{ml}$, lower than used in many studies. Our aim was to see how effective this dose is in controlling vertigo with minimal of hearing loss in our study. We gave only one injection \& followed the patients initially after 3 months with encouraging results.

Chia reported that low dose therapy results in lowest rate of vertigo control, but our results show that at 03 months $32 / 75(45.33 \%)$ patients had class A control and 29/75 (38.66\%) had class B control of vertigo. And at 02years $35 / 75$ (46.66\%) had class $A$ and in $33 / 75$ (44\%) patients had class $B$ control of vertigo. This means $91 \%$ patients $(45.33 \%+38.66 \%)$ had class A and B control of vertigo and were happy about the good control of vertigo they achieved with this dose (Table-VIII). Although our Class A vertigo control level was less than the studies using high dose regimens but around $91 \%$ patients had good control of vertigo. $4,8,10,11,12$ 
The hearing levels were assessed also and in only 6 patients had deterioration in PTA levels between $5-15 \mathrm{~dB}$. Of these only $3(4 \%)$ patients had a deterioration of $10 \mathrm{~dB}$ or more (According to AAO-HNS 1995 document PTA is considered improved or worse if a $10 \mathrm{~dB}$ or more difference is noted). This hearing preservation is better than studies using high dose regimens. The deterioration in hearing was transitory and improved in few months. ${ }^{13,14,15}$ Also our results are consistent with other studies using low dose gentamicin therapy. ${ }^{16,17,18}$ We believe that low dose gentamicin injection may have contributed to its lesser cochleotoxic effect as compared to high dose weekly injections in certain series. ${ }^{19}$

Our study had limitations as this was not blinded and patients were enrolled by convenience sampling and also there was no control group. More over we don't have other tools like Vestibular evoked myogenic potentials used by many studies now a days to assess the effect. But the fact is that patients do get benefit from Intratympanic gentamicin and majority is happy that after a long time of miserable life, they are finally enjoying it.

\section{CONCLUSIONS}

Single Low dose Intratympanic injection of gentamicin is effective in controlling vertigo in most patients with Meniere's disease with virtually no further deterioration in hearing. We conclude that total ablation of vestibular epithelium with high dose and repeated Intratympanic injection of gentamicin is not necessary to control vertigo. Vertigo can be controlled with low dose single intra tympanic injection of gentamicin, having low risk to hearing.

Copyright@ 12 Nov, 2015.

\section{REFERENCES}

1. Da Coata SS, De Sousa LC, Piza MR. Meniere's disease: Overview, epidemiology, and natural history. Otolarygol Clin North Am 2002; 35:455-95.

2. Minor LB, Schessel DA, Carey JP: Meniere's disease. Curr Opin Neurol 2004; 17:9-16.

3. Soderman AC, Bagger- Sjoback D, Bergenius J, Langius A. Factors influencing quality of life in patients with
Meniere's disease, identified by a multidimensional approach. Otol Neurotol 2002; 23:941-8.

4. Chia SH, Gamst AC, Anderson JP, Harris JP. Intratympanic gentamicin therapy for Meniere's disease: a meta-analysis. Otol Neurotol 2004; 25:54452.

5. Blakeley BW: Clinical Forum- a review of Intratympanic therapy. Am J Otol 1997; 18:520-31.

6. Okuda T, Sugahara K, Shimogori $H$, Yamashita $H$. Inner ear changes with intracochlear gentamicin administration in Gunea pigs. Laryngoscope 2004; 114:694-97.

7. Pullens B, Van Benthem PP. Intratympanic gentamicin for Meniere's disease or syndrome. Cochrane Database Syst Rev 2011; 16:CD008234.

8. Driscoll CL, Kasperbauer JL, Facer GW, Harner SG, Beatty CW. Low dose Intratympanic gentamicin and the treatment of Meniere's disease: Preliminary results. Laryngoscope 1997; 107:83-9.

9. Feng Zhai, Jian-Ping Liu, Chun-Fu Dai, Qi Wang, Peter S Steyger. Evidence-Based Modification of Intratympanic Gentamicin Injections in Patients with intractable Vertigo. Otol Neurotol 2010; 31(4):642-48.

10. Atlas JT, Parnes LS. Intratympanic gentamicin titration therapy for intractable Meniere's disease. Am J Otolarngol 1999; 20:357-63.

11. Kaplan DM, Nedzelski JM, Chen JM, Shipp DB. Intratympanic gentamicin for treatment of unilateral Meniere's disease. Laryngoscope2000; 2000:12981305.

12. Salt AN, Gill RM, Plontke SK. Dependence of hearing changes on the dose of intratympanically applied gentamicin: a meta-analysis using mathematical simulations of clinical drug delivery protocols. Laryngoscope 2008; 118:1793-800.

13. Abou-Halawa AS, Poe DS. Efficacy of increased gentamicin concentration for Intratympanic injection therapy in Meniere's disease. Otol neurotol 2002; 23:494-503.

14. Hirsch BE, Kamerer DB. Intratympanic gentamicin treatment for Meniere's disease. Am J Otol 1997; 18:44-51.

15. Rauch SD, Oas JG. Intratympanic gentamicin for treatment of intractable Meniere's disease: a preliminary report. Laryngoscope 1997; 107(1):49-55.

16. Sala T. Transtympanic gentamicin in the treatment of 
<Meniere's disease. Auris Nasus Larynx 1997; 24:23946.

17. Wu IC, Minor LB. Long-term hearing outcome in patients receiving Intratympanic gentamicin for Meniere's disease. Laryngoscope 2003; 113:815-20.

18. Chung WH, Chung KW, Kim JH, Cho YS, Hong SH. Effects of Intratympanic gentamicin injection on
Meniere's disease. Acta Otolaryngol Suppl. 2007; (558):61-6.

19. Martin E, Perez N. Hearing loss after intratympanic gentamicin therapy for unilateral Menier's Disease. Otol Neurotol.2003 Sept; 24(5):800-6.

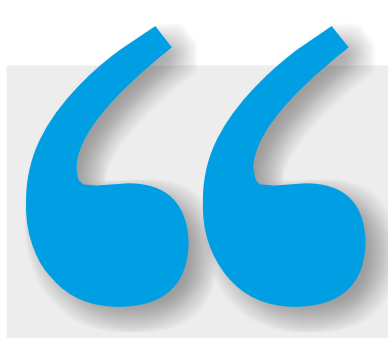

"There is no substitute for hard work."

\section{Thomas A Edison}

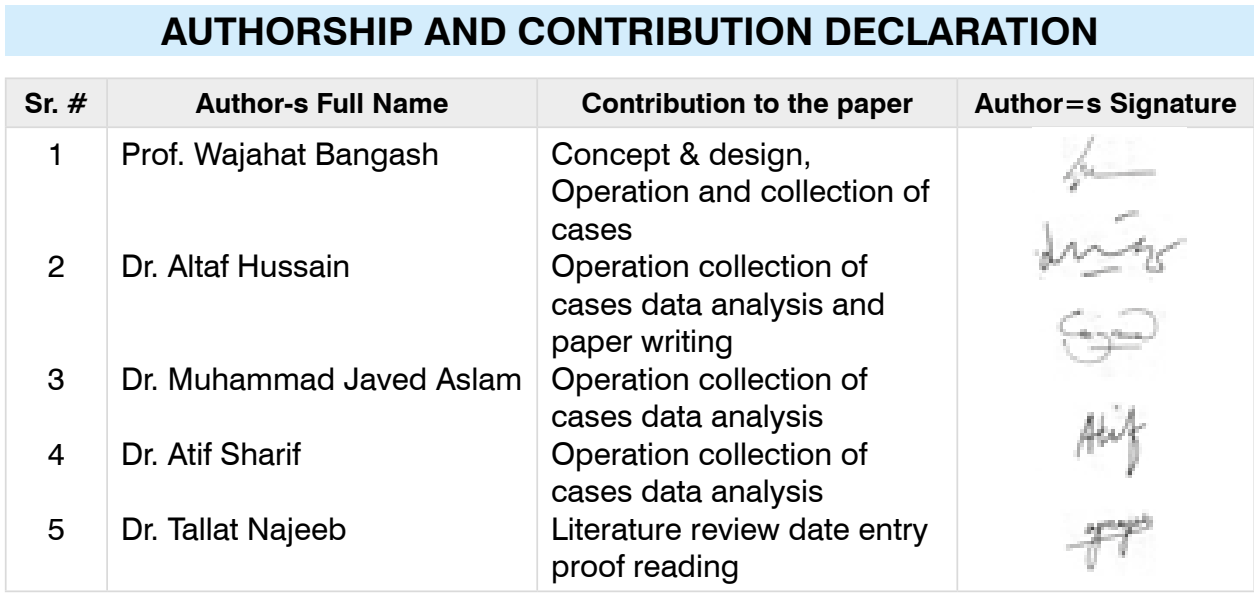

